\title{
Morphometric study of the blood supply of pedunculated colon polyps: What is the optimal position on the stalk for snare resection?
}

Authors

Institutions
Noriyuki Isohata' ${ }^{1}$, Daiki Nemoto ${ }^{1}$, Kenichi Utano ${ }^{1}$, Shungo Endo ${ }^{1}$, Gaku Tanaka ${ }^{2}$, David G. Hewett ${ }^{3,4}$, Kazutomo Togashi ${ }^{1}$

Institutions are listed at the end of article.
Bibliography

DOI http://dx.doi.org/

10.1055/s-0034-1393082

Published online: 6.10.2015

Endoscopy International Open

2015; 03: E655-E658

(c) Georg Thieme Verlag KG

Stuttgart $\cdot$ New York

E-ISSN 2196-9736

Corresponding author

\section{Kazutomo Togashi, MD, PhD}

21-2 Maeda, Tanisawa

Kawahigashi, Aizuwakamatsu

City

Fukushima, 969-3492

Japan

Phone: +81-242-75-2100

Fax: $+81-242-75-2568$

togashik@fmu.ac.jp
Background and study aims: Bleeding after colonoscopic resection of pedunculated polyps cannot be easily predicted. The aims of this study were to evaluate the blood supply in pedunculated polyps and to clarify the optimal position on the polyp stalk for snare placement to prevent post-polypectomy hemorrhage.

]Patients and methods: In one institution, 11 pedunculated polyps from 11 patients were studied prospectively. All polyps were resected at the base of the stalk using a snare wire with electrocautery. Histologic axial sections from the apex and base of the stalk were examined with hematoxylin eosin and elastica stains. Elastica stains were used to identify blood vessels. The crosssectional area of the stalk, total vessel area, maximum diameter of artery/arteriole lumen, number of thick ( $\geq 0.1 \mathrm{~mm}$ ) vessels, and number of arter-

\section{Introduction}

$\nabla$

Endoscopic polypectomy is a standard technique for treatment of colonic polyps, although it is associated with a risk of complications. The most common complication is hemorrhage after polypectomy [1], and delayed hemorrhage is known to occur in $0.3 \%$ to $6.1 \%$ of patients [2]. Several factors, including the patient's age, polyp size [3], location [4,5], morphology [6,7] and malignant potential [6], and concomitant anticoagulant therapy [8], are associated with bleeding. In addition, bleeding occurs more often after excision of sessile or pedunculated polyps with a broad stalk [3]. Large pedunculated polyps have larger vessels within the stalk [6].

Several techniques are available to prevent bleeding after colonoscopic polypectomy, including submucosal injection of epinephrine solution in the base of polyp [9], clip closure [10], detachable snare placement around the stalk [11] and development of the electrosurgical device [2]. However, no data are available to indicate the optimal ies/arterioles were measured in each section with image processing software. Wilcoxon signed-ranks test was used for comparison.

Results: The median polyp diameter was $16 \mathrm{~mm}$ (range 7 to $24 \mathrm{~mm}$ ) and median length of the stalk was $11 \mathrm{~mm}$ (range 7 to $23 \mathrm{~mm}$ ). Two invasive cancers (T1) were included. The maximum diameter of the arterial/arteriolar lumen was greater at the base $(P=0.0044)$, whereas the ratio of the vessel area to the cross-section area was greater at the apex $(P=0.016)$. The number of thick vessels and arteries/arterioles were equivalent between apex and base.

Conclusions: Morphometric study of the blood supply of pedunculated polyps confirmed that the optimal site for the excision of pedunculated polyps is in the middle of the stalk.

position for snare placement on the stalk to prevent hemorrhage following endoscopic resection of pedunculated polyps.

Pedunculated polypectomy in the middle of the stalk is recommended by experts [12]. Excision away from the head of the polyp is advised to minimize margin involvement in the case of invasive cancer. Conversely, excision at the base of the stalk is not advised due to the potential for perforation. Although these risks form the theoretical basis for conventional recommendations to excise at the middle of the stalk, supporting evidence for this approach is lacking. Information about the blood supply to pedunculated polyps may guide the approach to endoscopic resection. In this study, we conducted a morphometric analysis of the blood supply to the stalk of pedunculated colon polyps. Our goal was to clarify the optimal position on the stalk for snare resection of pedunculated polyps. 


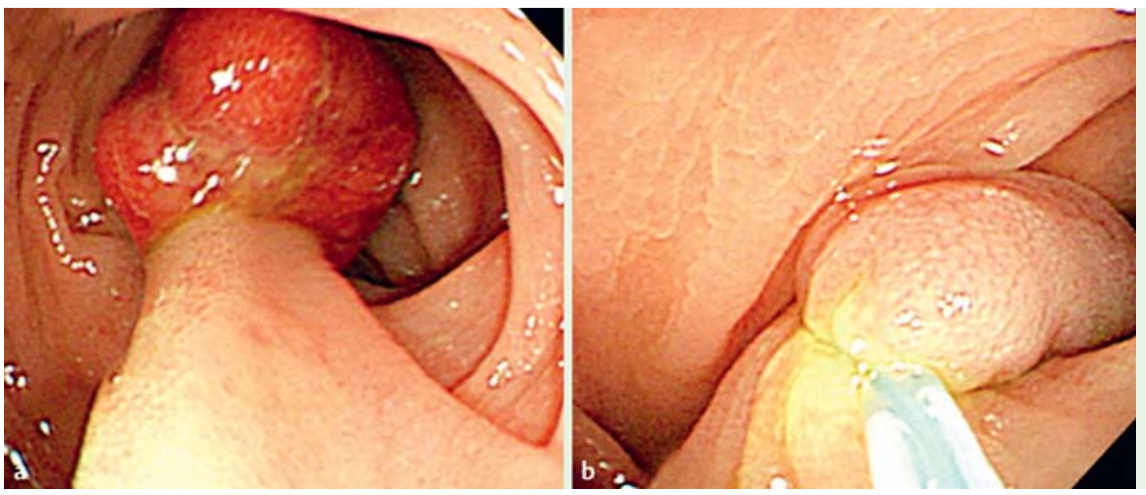

Fig. 1 a A pedunculated polyp with large head and long stalk in the sigmoid colon. $\mathbf{b}$ The polyp was resected at the base of the stalk using a snare with electrocautery.
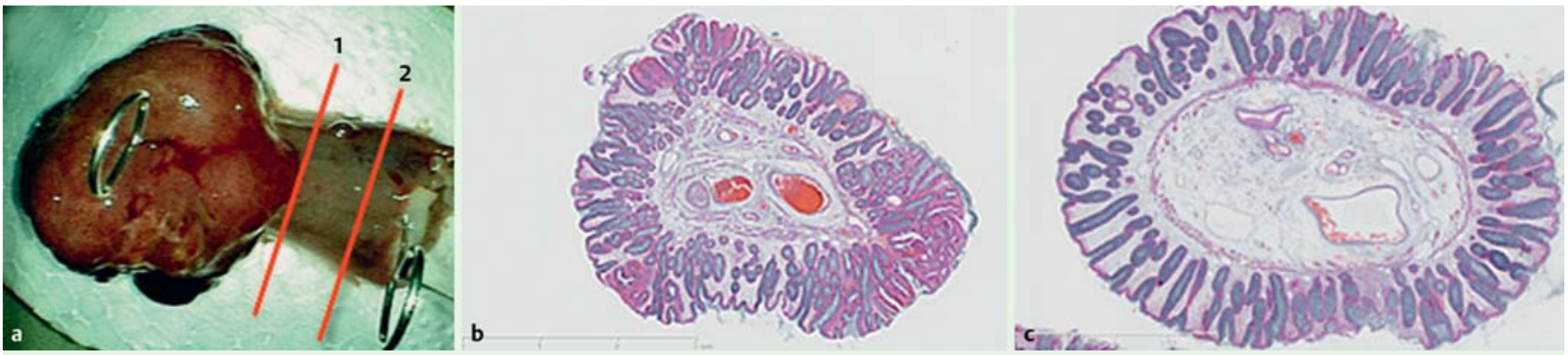

Fig. 2 a Histologic cross-sections from the apex and base of the stalk were obtained from each resected polyp. $\mathbf{b}$ Hematoxylin eosin stain of the stalk in cross section near the head (a, (1)). c hematoxylin eosin stain of the stalk in cross section near the base (a, (2)).

\section{Patients and methods}

$\nabla$

\section{Participants}

Before study commencement, the local committee on human experimentation approved this study. We conducted a prospective study in a single center. From April 2011 to November 2012, 11 patients with pedunculated polyps (median age 63 years, range: 37 to 87; all male) were enrolled non-consecutively at our academic endoscopy center. Patients whose pedunculated polyps were suspected to have malignant stalk invasion were excluded. Written informed consent to examine the resected specimens was obtained from all patients after colonoscopic resection.

\section{Endoscopic polypectomy procedure}

All patients received bowel preparation with 2 or $3 \mathrm{~L}$ of polyethylene glycol electrolytic solution (Niflec: Ajinomoto, Tokyo, Japan). To minimize damage from electrocautery and allow precise evaluation of the histology of the stalk, polypectomy was carried out using thin snare wires $(0.3 \mathrm{~mm}$ diameter, SD-230U25 , Olympus, Tokyo) without submucosal injection. All polyps were resected using electrocautery with the ICC 200 electrosurgical generator (ERBE, Tubingen, Germany): Endocut, effect 3 (output limit 120W). All polyps were resected at the base of the stalk. An example endoscopic image is shown in $\bullet$ Fig. 1. All resected specimens were pinned immediately after resection on a board ( $\bullet$ Fig. 2). Before formalin fixation, the maximum diameter of the polyp head, the maximum diameter of the stalk, and the length of the stalk were measured with calipers.

\section{Histologic examination}

All resected polyps were fixed and embedded in paraffin. Axial sections from the head and base of all stalks were obtained and stained with hematoxylin eosin and elastica ( $\boldsymbol{O}$ Fig. 3 ). Arteries and arterioles were defined as blood vessels possessing the inter-

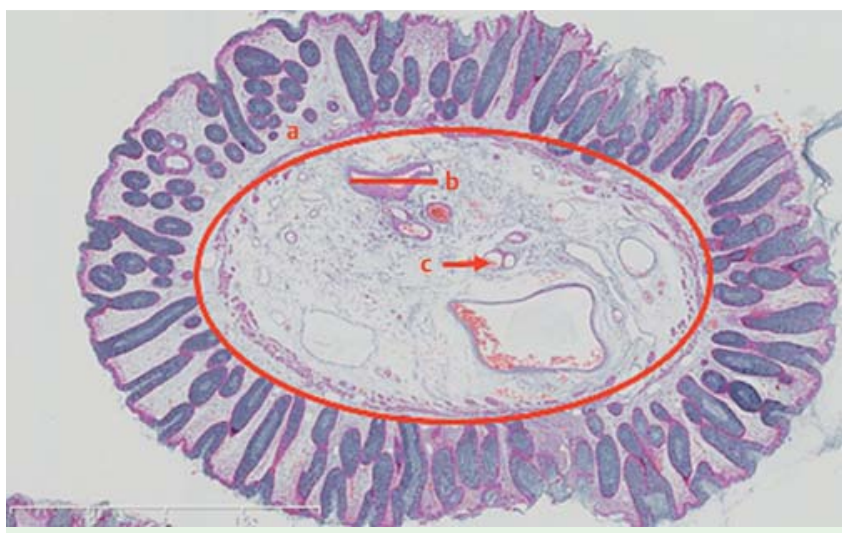

Fig. 3 The cross-sectional area of the stalk. a maximum diameter of arteriole lumen. $\mathbf{b}$ and number of the vessels measuring $0.1 \mathrm{~mm}$ or greater c were measured with image processing software (Image J).

nal elastic membrane of the intima, identified with elastica stains. To discriminate lymphatic channels from blood vessels, D2 - 40 stains were performed on the first three cases. However, very few lymphatic vessels were recognizable in sections. Therefore, in this study, all vessels are defined as blood vessels.

\section{Image analyses}

All histologic images were processed with a virtual pathology system (Nanozoomer digital pathology, Hamamatsu photonics, Japan). The cross-sectional area of the stalk, total vessel area, number of vessels measuring $\geq 0.1 \mathrm{~mm}$, number of arteries/arterioles (possessing internal elastic membrane), and maximum diameter of arteries/arterioles lumen were measured with image processing software (Image J [13]). The cross-sectional area of the stalk was defined as the area excluding the epithelial layer (० Fig.4). 

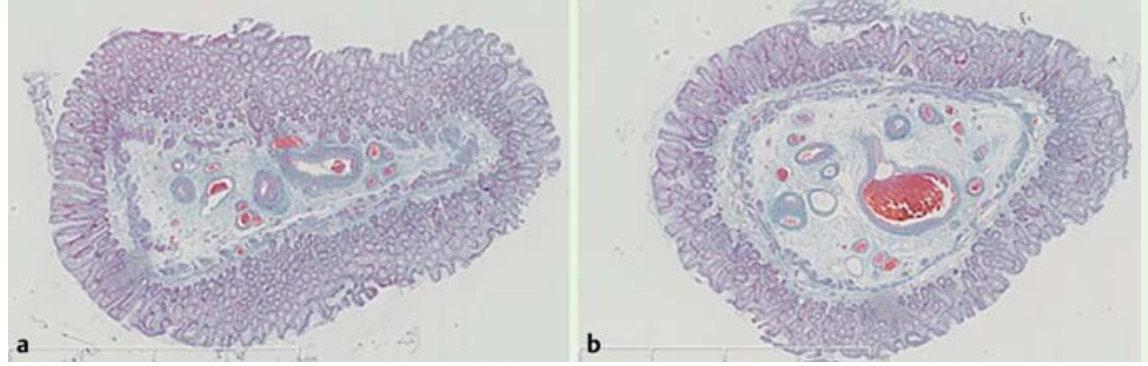

Fig. 4 a Cross-sectional area of the stalk apex. b Cross-sectional area of the stalk base. Two different sections from the same polyp are shown. The maximum diameter of the arteries/arterioles lumen in the base is greater than that of the apex. In contrast, the ratio of the vessels to the cross section is greater in the apex than the base. However, the vessel area, number of vessels, and number of arteries/arterioles are equivalent between the apex and base.

Table 1 Characteristics of 11 polyps

\begin{tabular}{|c|c|c|c|c|c|}
\hline Polyp & Location & $\begin{array}{l}\text { Maximum diameter } \\
\text { of the head }(\mathrm{mm})\end{array}$ & $\begin{array}{l}\text { Maximum diameter } \\
\text { of the stalk (mm) }\end{array}$ & Length of the stalk (mm) & Histology \\
\hline 1 & Sigmoid & 15 & 12 & 13 & Cancer in situ, tub2 ${ }^{1}$ \\
\hline 2 & Sigmoid & 12 & 9 & 11 & tubular adenoma, high-grade \\
\hline 3 & Sigmoid & 24 & 12 & 8 & $\mathrm{~T} 1^{2}$, tub13 \\
\hline 4 & Sigmoid & 20 & 5 & 12 & Tubular adenoma, high-grade \\
\hline 5 & Sigmoid & 16 & 12 & 8 & $\mathrm{~T} 1^{2}$, tub13 \\
\hline 6 & Ascending & 7 & 5 & 7 & Tubular adenoma, low-grade \\
\hline 7 & Ascending & 10 & 10 & 12 & Tubular adenoma, low-grade \\
\hline 8 & Sigmoid & 18 & 7 & 11 & Tubular adenoma, low-grade \\
\hline 9 & Sigmoid & 14 & 7 & 8 & Tubulovillous adenoma \\
\hline 10 & Sigmoid & 22 & 13 & 9 & Traditional serrated adenoma \\
\hline 11 & Ascending & 16 & 7 & 16 & Cancer in situ, tub $1^{3}$ \\
\hline
\end{tabular}

1 moderately differentiated type tubular adenocarcinoma

2 tumor invading submucosal layer

${ }^{3}$ well-differentiated type tubular adenocarcinoma

Table 2 Comparison between apex and base

\begin{tabular}{|llllll} 
& Apex & & Base & & \\
& Median & Range & Median & Range & P-value \\
\hline Cross-section area $\left(\mathrm{mm}^{2}\right)$ & 7.89 & $0.74-23.0$ & 10.31 & $1.54-26.5$ & $\mathbf{0 . 0 0 9 9}$ \\
\hline Vessel area $\left(\mathrm{mm}^{2}\right)$ & 1.58 & $0.14-4.10$ & 1.07 & $019-3.78$ & 0.72 \\
\hline Ratio of CSA' to vessel area & 0.18 & $0.07-0.30$ & 0.13 & $0.07-0.24$ & $\mathbf{0 . 0 1 6}$ \\
\hline No. of vessels $(\geq 0.1 \mathrm{~mm})$ & 43 & $12-72$ & 43 & $15-86$ & 0.96 \\
\hline No. of arteries/arterioles & 3 & $1-$ & 3 & $2-$ & 0.37 \\
\hline Maximum size of arteriole $(\mathrm{mm})$ & 0.48 & $0.08-1.53$ & 0.74 & $0.15-1.66$ & $\mathbf{0 . 0 0 4 4}$ \\
\hline
\end{tabular}

Significant P-values are expressed in bold.

${ }^{1}$ cross-section area.

\section{Statistics}

The cross-sectional area of the stalk, total vessel area, number of vessels measuring $\geq 0.1 \mathrm{~mm}$, number of arteries/arterioles and maximum diameter of arteries/arterioles lumen were compared between the apex and base of the stalk, using the Wilcoxon signed-ranks test. The ratio of total vessel area to cross-sectional area also was analyzed. The criterion for statistical significance was $P<0.05$. All statistical analyses were performed with Stata 11.0 (Stata Corp., TX, USA)

\section{Results}

$\nabla$

Characteristics of the polyps in the 11 patients studied are shown in $\odot$ Table 1. Eight polyps were located in the sigmoid colon and three in the ascending colon. The median size of the polyp head was $16 \mathrm{~mm}$ (range $7-24 \mathrm{~mm}$ ) and median stalk length was $11 \mathrm{~mm}$ (range $7-23 \mathrm{~mm}$ ). Two of the polyps were
T1-stage cancers (submucosal invasion depth: $950 \mu \mathrm{m}$ and $1000 \mu \mathrm{m}$ ), and were included in the analyses.

- Table 2 shows findings for the cross-sectional area of the stalk, total vessel area, number of vessels measuring $\geq 0.1 \mathrm{~mm}$, number of arteries/arterioles, and maximum diameter of arteries/arterioles lumen. The cross-sectional area was greater at the base than the apex of the stalk $\left(10.31 \mathrm{~mm}^{2}\right.$ vs. $\left.7.89 \mathrm{~mm}^{2 ;} P=0.01\right)$, as was the maximum luminal diameter of stalk arteries/arterioles $(0.74 \mathrm{~mm}$ vs $0.48 \mathrm{~mm} ; P=0.004)$. In contrast, the ratio of vessel area to the cross-sectional area was greater in the apex than in the base ( 0.18 vs. $0.13 ; P=0.016)$. There was no statistical difference between the apex and the base in total vessel area, number of the vessels measuring $\geq 0.1 \mathrm{~mm}$, and number of arteries/arterioles. In subgroup analysis by location, significant differences in cross-sectional area of the stalk and the maximum luminal diameter of stalk arteries/arterioles persisted only in polyps from the sigmoid colon and not those in the ascending colon, although the sample size was limited. 


\section{Discussion}

$\nabla$

To our knowledge, the microscopic blood supply of the stalk of pedunculated colon polyps has been the focus of limited study. Because it is challenging to evaluate the quantity of blood supply in real time, we chose instead to investigate the histology of the vessels in the stalk. The density, diameter, and morphology of the vessels were used as surrogate markers for blood supply. We searched PubMed using the terms "pedunculated polyp" and "blood supply" and found only one report on this issue. Dobrowolski et al. studied perpendicular sections of the mucosal surface to assess microscopic blood supply [6]. That approach might not be sufficient for morphometric study of vessel number and diameter because the vessels run longitudinally in the stalk. In contrast, we used axial sections of the stalks, easily identifying the exact number of vessels, as well as the maximum diameter of the vessels on a pathology slide. Indeed, the number of vessels measuring $\geq 100 \mu \mathrm{m}$ was much higher in our study using axial section, compared with Dobrowolski and colleagues' study, which used longitudinal section (15-86 vs. $1-4$ at the base of the stalk).

Our study has shown that the total vessel area, number of vessels measuring $\geq 100 \mu \mathrm{m}$, and number of arteries/arterioles did not differ between the apex and the base of the stalk. Our results suggest that the stalk position for snare resection of pedunculated colon polyps is not relevant for prevention of hemorrhage after resection. Nevertheless, oncologic aspects are important, because our 11 polyps included two invasive cancers. Although resection close to the polyp head is safer for avoiding perforation, a sufficient margin is required to achieve complete resection of invasive cancer. Therefore, resection close to the head is not optimal from an oncologic perspective.

It is our practice to primarily apply prophylactic clipping after resection of pedunculated polyps to fully close the resection site on the stump of the residual stalk. In our experience, with delayed bleeding after pedunculated polyp resection, bleeding occurs at the edge of the stump.Our series has shown that the stalk contains a far higher number of vessels than previously expected. Accordingly, complete closure by clipping may be ideal for eradication of delayed bleeding, even though it can be more difficult to achieve technically. Stalk vessel number may explain the lower reported efficacy of prophylactic clipping after polypectomy.[10, $14,15]$

There are acknowledged limitations to our study. Its small size limits the generalizability of the results. Despite that, we believe that the information presented here regarding the blood supply of pedunculated polyps is useful to colonoscopists.

In conclusion, morphometric study of the blood supply of pedunculated polyps confirmed that the optimal site for excision of pedunculated polyps is in the middle of the stalk, as recommended by experts. [12] In addition, our findings that the stalk contains a greater number of vessels than previously expected may explain why delayed bleeding can occur even after prophylactic clipping.

\section{Competing interests: None}

Institutions

Department of Coloproctology, Aizu Medical Center Fukushima Medical University, Japan

2 Department of Pathology, Aizu Medical Center, Fukushima Medical University, Japan

${ }^{3}$ University of Queensland School of Medicine, Brisbane, Australia

${ }^{4}$ Department of Gastroenterology, Queen Elizabeth II Jubilee Hospital, Brisbane, Australia

\section{Acknowledgement}

$\nabla$

We appreciate technical supports by Professor Hiroshi Hojo, Mr. Takashi Sato, Ms. Michie Kojimahara, and Ms. Miwa Sagawa, in Department of Pathology, Aizu Medical Center, Fukushima Medical Uiversity.

\section{References}

1 Dominitz JA, Eisen GM, Baron TH et al. Complications of colonoscopy. Gastrointest Endosc 2003; 57: 441-445

2 Rosen L, Bub DS, Reed JF 3rd et al. Hemorrhage following colonoscopy polypectomy. Dis Colon Rectum 1993; 36: 1126 - 1131

3 Macrae FA, Tan GK, Williams CB. Towards safer colonoscopy: a report on the complication of 5000 diagnostic or therapeutic colonoscopies. Gut 1983; 24: 376-381

4 Rex DK, Lewis BS, Waye JD. Colonoscopy and endoscopic therapy for delayed post-polypectomy hemorrhage. Gastrointest Endosc 1992; 38: $127-129$

5 Buddingh KT, Herngreen T, Haringsma $J$ et al. Location in the right hemi-colon is an independent risk factor for delayed post-polypectomy hemorrhage: a multi-center case-control study. Am J Gastroenterol 2011; 106: 1119-1124

6 Dobrowolski S, Dobosz M, Babicki A et al. Blood supply of colorectal polyps correlates with risk of bleeding after colonoscopic polypectomy. Gastrointest Endosc 2006; 63: 1004-1009

7 Sorbi D, Norton I, Conio M et al. Postpolypectomy lower GI bleeding: descriptive analysis. Gastrointest Endosc 2000; 51: 690-696

8 Hui AJ, Wong RM, Ching JY et al. Risk of colonoscopic polypectomy bleeding with anticoagulants and antiplatelet agents: analysis of 1657 cases. Gastrointest Endosc 2003; 59: $44-48$

9 Di Giorgio P, De Luca L, Calcagno G et al. Detachable snare versus epinephrine injection in the prevention of postpolypectomy bleeding: a randomized and controlled study. Endoscopy 2004; 36: 860-863

10 Liaquat $H$, Roth E, Rex DK. Prophylactic clip closure reduced the risk of delayed postpolypectomy hemorrhage: experience in 277 clipped large sessile or flat colorectal lesions and 247 control lesions. Gastrointest Endosc 2013: 77; 401-407

11 Lishi $H$, Tatsuta M, Narahara $H$ et al. Endoscopic resection of large pedunculated colorectal polyps using a detachable snare. Gastrointest Endosc 1996; 44: 594-597

12 Waye JD, Rex DK, Williams CB. Colonoscopy: Principles and Practice. Second edition Hoboken, NJ: Wiley-Blackwell; 2009: 578-579

13 Schneider CA, Rasband WS, Eliceiri KW. NIH Image to Image: 25 years of image analysis. Nature Methods 2012; 9: 671 -675

14 Feagins $L A$, Nguyen $A D$, Iqbal $R$ et al. The prophylactic placement of hemoclips to prevent delayed post-polypectomy bleeding: an unnecessary practice? A case control study Dig Dis Sci 2014; 59: 823-828

15 Shioji K, Suzuki Y, Kobayashi M et al. Prophylactic clip application dose not decrease delayed bleeding after colonoscopic polypectomy. Gastrointest Endosc 2003; 57: 691-694 